ORNL/TM-2013/581

\title{
Residential Variable-Capacity Heat Pumps Sized to Heating Loads
}

\section{January 2014}

\section{Prepared by}

Jeffrey Munk, Oak Ridge National Laboratory Adewale Odukomaiya, Georgia Institute of Technology Roderick Jackson, Ph.D., Oak Ridge National Laboratory Anthony Gehl, Oak Ridge National Laboratory 


\section{DOCUMENT AVAILABILITY}

Reports produced after January 1, 1996, are generally available free via the U.S. Department of Energy (DOE) Information Bridge.

Web site http://www.osti.gov/bridge

Reports produced before January 1, 1996, may be purchased by members of the public from the following source.

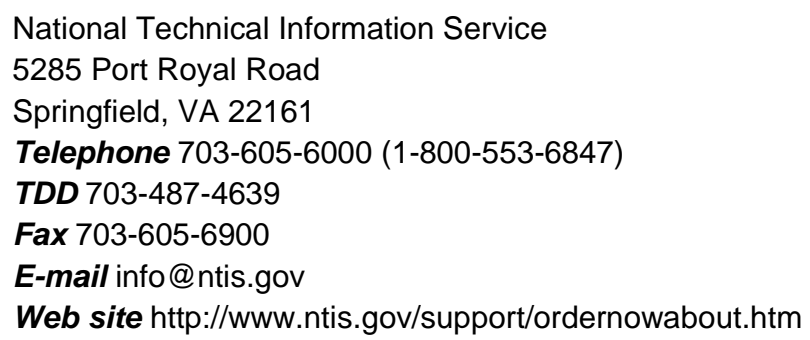

Reports are available to DOE employees, DOE contractors, Energy Technology Data Exchange (ETDE) representatives, and International Nuclear Information System (INIS) representatives from the following source.

Office of Scientific and Technical Information

P.O. Box 62

Oak Ridge, TN 37831

Telephone 865-576-8401

Fax 865-576-5728

E-mail reports@osti.gov

Web site http://www.osti.gov/contact.html

This report was prepared as an account of work sponsored by an agency of the United States Government. Neither the United States Government nor any agency thereof, nor any of their employees, makes any warranty, express or implied, or assumes any legal liability or responsibility for the accuracy, completeness, or usefulness of any information, apparatus, product, or process disclosed, or represents that its use would not infringe privately owned rights. Reference herein to any specific commercial product, process, or service by trade name, trademark, manufacturer, or otherwise, does not necessarily constitute or imply its endorsement, recommendation, or favoring by the United States Government or any agency thereof. The views and opinions of authors expressed herein do not necessarily state or reflect those of the United States Government or any agency thereof. 
Energy and Transportation Science Division

Residential Variable-Capacity Heat Pumps Sized to Heating Loads

Date Published: January 2014

Jeffrey Munk, Oak Ridge National Laboratory

Roderick Jackson, Ph.D., Oak Ridge National Laboratory

\section{Prepared by \\ OAK RIDGE NATIONAL LABORATORY}

Oak Ridge, Tennessee 37831-6283

managed by

UT-BATTELLE, LLC

for the

U.S. DEPARTMENT OF ENERGY

under contract DE-AC05-00OR22725 



\section{CONTENTS}

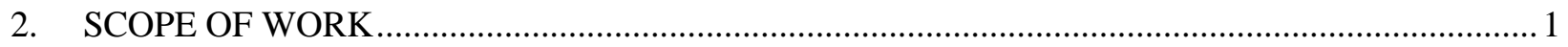

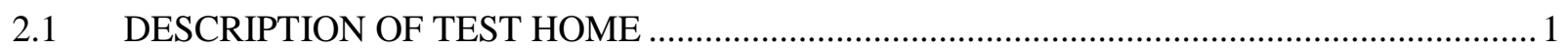

2.2 DESCRIPTION OF EQUIPMENT AND SIZING ...................................................... 2

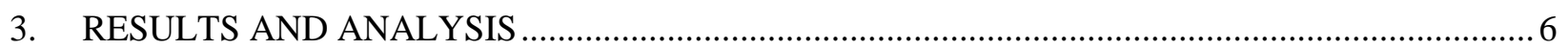

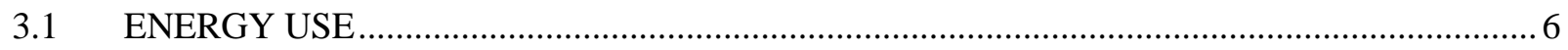

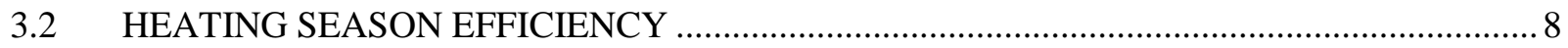

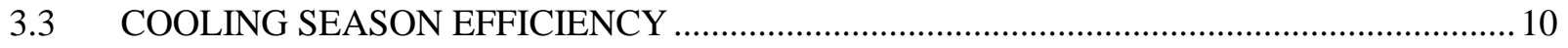

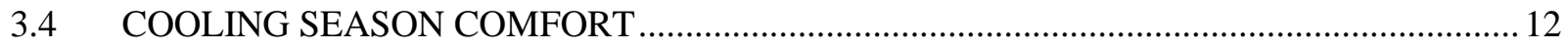

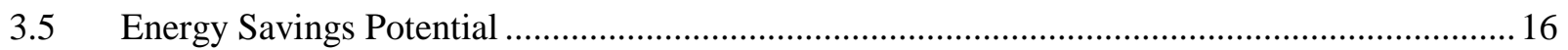

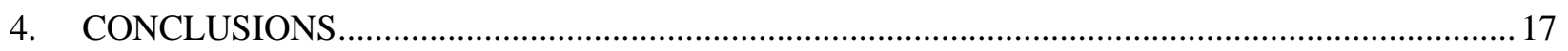

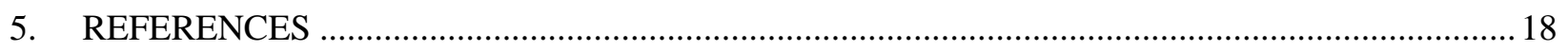

\section{FIGURES}

Fig. 1. Level-1 Maximum Capacity and Delivered Capacity ............................................................... 3

Fig. 2. CC1 Level-2 Maximum Heating Capacity and Delivered Capacity .............................................. 4

Fig. 3. CC1 Level-1 Maximum Total Cooling Capacity and Delivered Capacity .......................................5

Fig. 4. CC1 Level-2 Maximum Total Cooling Capacity and Delivered Capacity ......................................5

Fig. 5. CC1 TMY3 Annual Energy Use for Knoxville, Tennessee ........................................................... 7

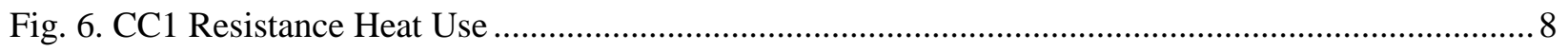

Fig. 7. CC1 Level-2 Heating Efficiency Before and After Added Charge ............................................... 9

Fig. 8. CC1 Level-1 and Level-2 Hourly Part Load Ratios ................................................................... 10

Fig. 9. CC1 Cooling Season Hourly Part Load Ratios............................................................................ 12

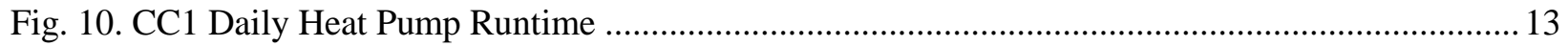

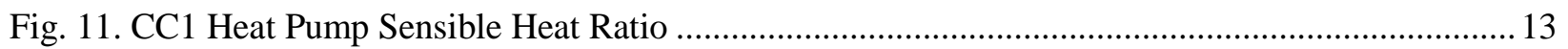

Fig. 12. CC1 Level-1 Indoor Relative Humidity Levels.................................................................... 14

Fig. 13. CC1 Level-2 Indoor Relative Humidity Levels................................................................... 15

Fig. 14. Sensible Heat Ratio vs. Indoor Relative Humidity ............................................................ 16 



\section{INTRODUCTION}

Variable capacity heat pumps are an emerging technology offering significant energy savings potential and improved efficiency. With conventional single-speed systems, it is important to appropriately size heat pumps for the cooling load as over-sizing would result in cycling and insufficient latent capacity required for humidity control. These appropriately sized systems are often under-sized for the heating load and require inefficient supplemental electric resistance heat to meet the heating demand. Variable capacity heat pumps address these shortcomings by providing an opportunity to intentionally size systems for the dominant heating season load without adverse effects of cycling or insufficient dehumidification in the cooling season. This intentionally-sized system could result in significant energy savings in the heating season, as the need for inefficient supplemental electric resistance heat is drastically reduced. This is a continuation of a study evaluating the energy consumption of variable capacity heat pumps installed in two unoccupied research homes in Farragut, a suburb of Knoxville, Tennessee. In this particular study, space conditioning systems are intentionally sized for the heating season loads to provide an opportunity to understand and evaluate the impact this would have on electric resistance heat use and dehumidification.

The results and conclusions drawn through this research are valid and specific for portions of the Southeastern and Midwestern United States falling in the mixed-humid climate zone. While other regions in the U.S. do not experience this type of climate, this work provides a basis for, and can help understand the implications of other climate zones on residential space conditioning energy consumption. The data presented here will provide a framework for fine tuning residential building EnergyPlus models that are being developed.

\section{SCOPE OF WORK}

\subsection{DESCRIPTION OF TEST HOME}

This study is based on measurements taken from a test home (CC1) that has been outfitted with ducted heat pumps having inverter-driven, variable-speed compressors from the same manufacturer. The home is extensively instrumented with data acquisition systems monitoring energy use and space conditioning equipment performance. The home is unoccupied, but occupancy is simulated by controlling lighting, shower, appliance, and sensible and latent building loads. These loads are cycled on and off at regularly scheduled times, and latent and sensible loads are simulated as described in Boudreaux, Gehl, and Christian (2012). The home is located in the Campbell Creek subdivision of Farragut, Tennessee. Data is available from the single-speed heat pump systems that were previously installed in $\mathrm{CC} 1$ and will be used for comparison to provide a reference for a more conventional space conditioning system. The home is maintained at heating and cooling season set points of $71^{\circ} \mathrm{F}$ and $76^{\circ} \mathrm{F}$, respectively and is monitored via thermistors located near the thermostats.

This home uses standard regional construction methods and is used for baseline comparisons of space conditioning energy consumption for two other research homes constructed in the Campbell Creek 
subdivision. $\mathrm{CC} 1$ is considered a typical builder home and meets the 2006 International Energy Conservation Code (IECC) (International Code Council, 2006). It is two stories tall, with $953 \mathrm{ft}^{2}$ downstairs and $1,369 \mathrm{ft}^{2}$ upstairs.

\subsection{DESCRIPTION OF EQUIPMENT AND SIZING}

The space conditioning system consists of two, variable speed, air-source heat pumps, one for each of the two zones (upstairs and downstairs). The upstairs heat pump has 3-tons of nominal cooling capacity, while the downstairs heat pump has 2-tons. These heat pumps consist of an inverter-driven compressor outdoor unit coupled to a ducted air handling unit. The upstairs air handling unit sits in the attic, while the downstairs unit is installed in the garage. Each indoor unit utilizes a variable-speed blower with a brushless permanent magnet (BPM) motor as well as $5 \mathrm{~kW}$ auxiliary electric resistance heat elements. Each unit can operate in two different modes: efficiency mode and comfort mode. In comfort mode the units run at lower indoor airflow rates, and in the cooling mode the system can reduce the airflow further in an attempt to maintain indoor humidity below the set point. In efficiency mode the unit runs at higher airflow rates and indoor humidity is not directly controlled.

As previously mentioned, the space conditioning systems were sized to the dominant heating season load. Fig. 1 and Fig. 2 show maximum heating capacity of the two HPs based on the manufacturer's product data, the average hourly heating capacity from the measured data, and the Air Conditioning Contractors of America (ACCA) Manual J heating design loads (Rutkowski, 2006). The error bars on the measured data show the band of \pm 2 standard deviations from the average to give the reader a sense of how much spread was seen in the data. It should be noted that the Manual J heating design load calculation does not take into account internal loads that would decrease the heating load on the house, e.g., people, lights, equipment, and appliances (Elite, 2011). Due to this fact, it is expected that Manual J design heating load would be higher than the actual measured data.

The average measured heating capacity of the level-1 unit comes very close to the Manual $\mathrm{J}$ design heating capacity, and exceeded it during some hours. The data indicates that the unit would require supplemental resistance heating during some hours when the outdoor air temperature (OAT) reached approximately $15^{\circ} \mathrm{F}$. With a heating design OAT of $19^{\circ} \mathrm{F}$, the unit has very little excess heating capacity for this climate. 


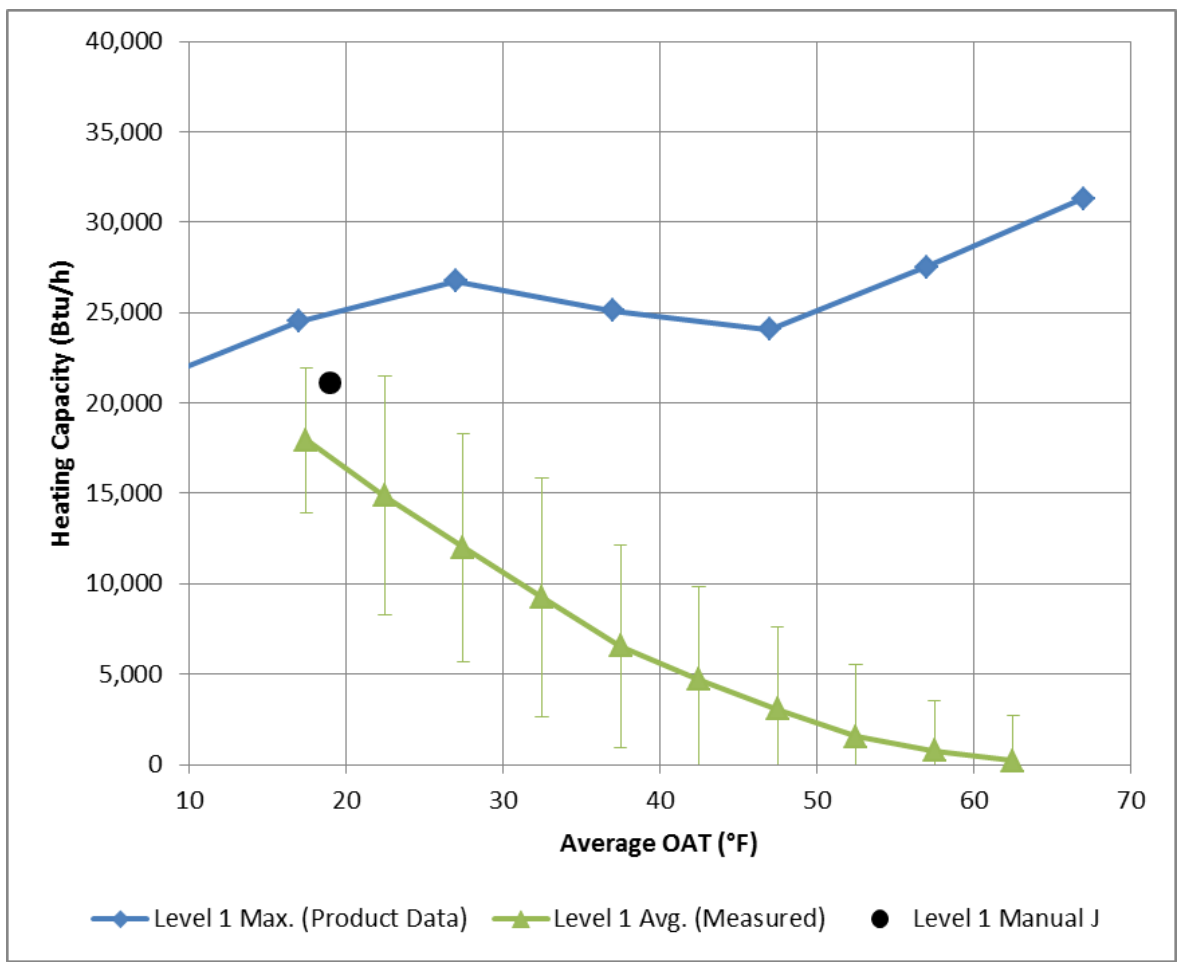

Fig. 1. Level-1 Maximum Heating Capacity and Average Hourly Delivered Capacity

The level-2 unit delivered substantially less heat than the level-1 system at low OATs and less than half of the Manual J design heating load at $19^{\circ} \mathrm{F}$ OAT. The unit only delivers approximately $1 / 3$ of its maximum heating capacity based on the manufacturer's product data at this OAT, indicating that this unit is substantially oversized for the heating load it is providing.

It should be noted that the level-1 unit appears to carry a larger portion of the total house heating load as the OAT decreases. It can be seen in Fig. 1 and Fig. 2 that the average measured capacities of the two units are nearly identical around an OAT of $40^{\circ} \mathrm{F}$, but diverge significantly at OATs of $30^{\circ} \mathrm{F}$ and lower. It was observed that the level-2 temperature increased when the level-1 unit was heating and the level-2 unit was off. This indicates that some of the heat being provided by the level-1 unit was rising to the upstairs of the home. The Manual J load calculation does not account for this phenomenon, which explains why the Manual J heating load for the level-2 unit is so much higher than the delivered load while the level-1 Manual $\mathrm{J}$ heating load is unexpectedly close to the delivered load. 


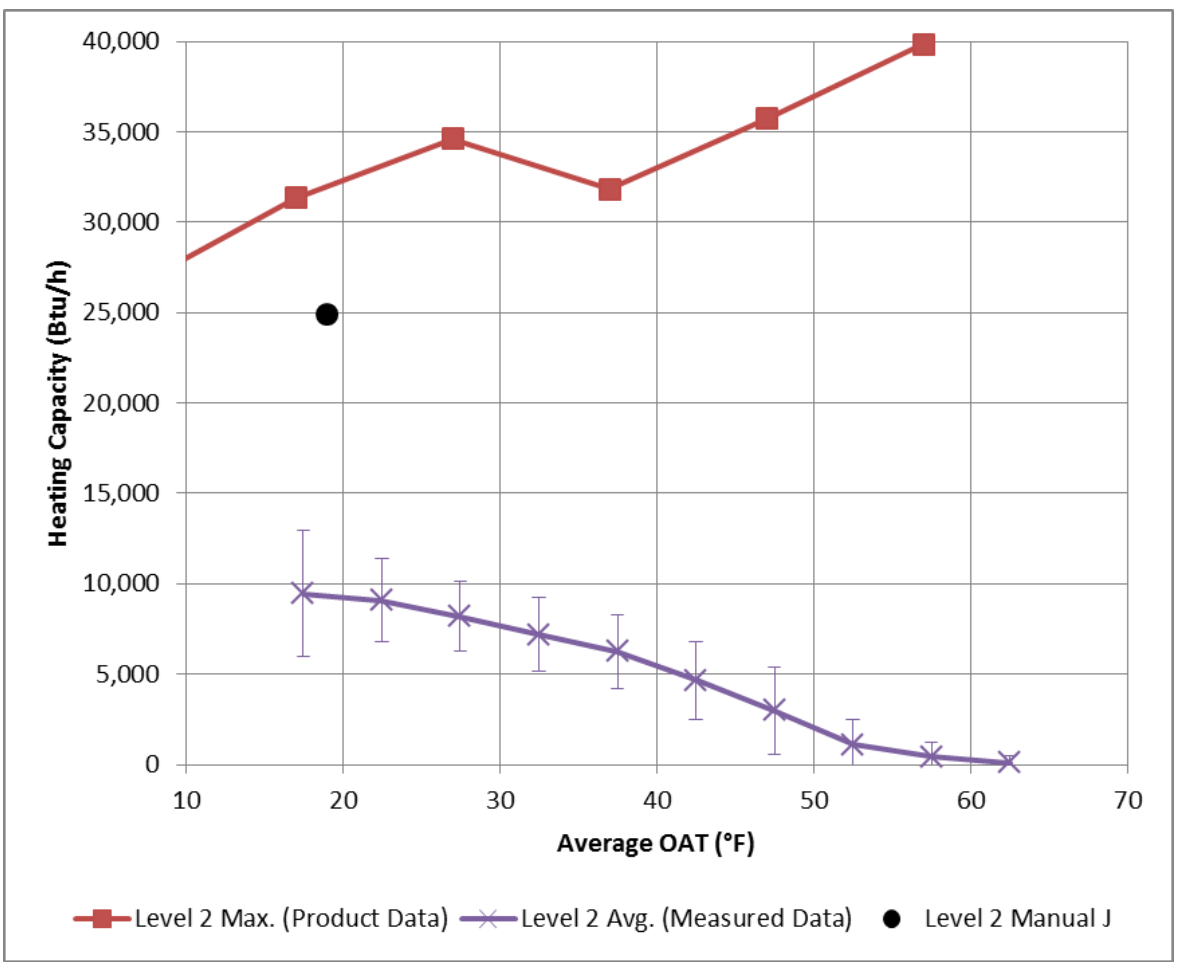

Fig. 2. Level-2 Maximum Heating Capacity and Average Hourly Delivered Capacity

Since the units were sized for the heating load, it is expected that they will be oversized for the cooling load. ${ }^{1}$ Fig. 3 and Fig. 4 show the maximum total cooling capacity from the manufacturer's product data, the average total cooling capacity from the measured data, and the Manual $\mathrm{J}$ design cooling load. The error bars on the measured data show the band of \pm 2 standard deviations from the average to give the reader a sense of how much spread was seen in the data. It should be noted that the Manual J cooling design load calculation does not take into account loads that would decrease the heating load on the house, e.g., heat loss through the slab foundation (Elite, 2011). Due to this fact, it is expected that Manual J design cooling load would be higher than the actual measured data for the level-1 unit.

The average measured total cooling capacity for the level-1 unit is extremely low and relatively insensitive to changes in the OAT. Due to a mild summer, measured data is not available for OATs over $92^{\circ} \mathrm{F}$; however, the capacity trend with OAT can be reasonably represented by a linear trendline (dotted line in the figure). This trendline indicates an average cooling load of only $4,000 \mathrm{Btu} / \mathrm{h}$ at the design temperature of $97^{\circ} \mathrm{F}$. This is less than half of the Manual J design load and less than one-fifth of the maximum cooling capacity of the unit based on the manufacturer's product data. The spread of the data was reasonably small as well indicating that the peak cooling load at $97^{\circ} \mathrm{F}$ may only be around 8,000 $\mathrm{Btu} / \mathrm{h}$. This data indicates that the unit has roughly three times the required cooling capacity and is therefore substantially oversized.

\footnotetext{
${ }^{1}$ On average in Knoxville there are 3,614 heating degree days and 1,451 cooling degree days with a base temperature of $65^{\circ} \mathrm{F}$.
} 


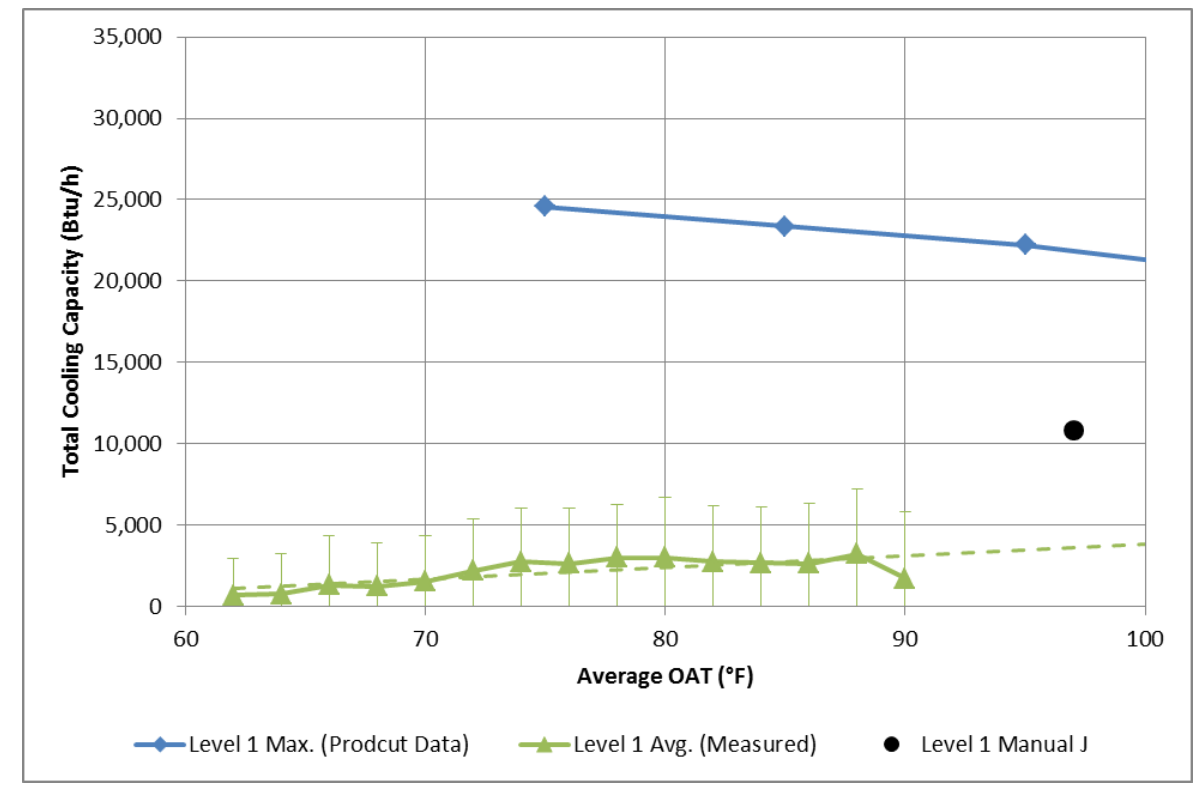

Fig. 3. Level-1 Maximum Total Cooling Capacity and Average Hourly Delivered Capacity

The level-2 unit delivered much more cooling than the level-1 unit as seen in Fig. 4. This was expected to some extent as seen by the Manual $\mathrm{J}$ design cooling load being roughly double that of the level-1 unit. The majority of this difference is driven by duct losses to the unconditioned attic, heat gain from the attic, and more volume to condition due to the bonus room over the garage. The linear trendline (dotted line) indicates that the average measured capacity of the system would exceed the Manual J design cooling load at $97^{\circ} \mathrm{F}$ OAT. There is substantially more spread in the data as well, which is likely due to more exposed windows on the second floor causing larger variations in solar gains as well as the lag in attic heat gains with respect to OAT. These larger variations indicate that the unit is probably very close to the proper size for the cooling load.

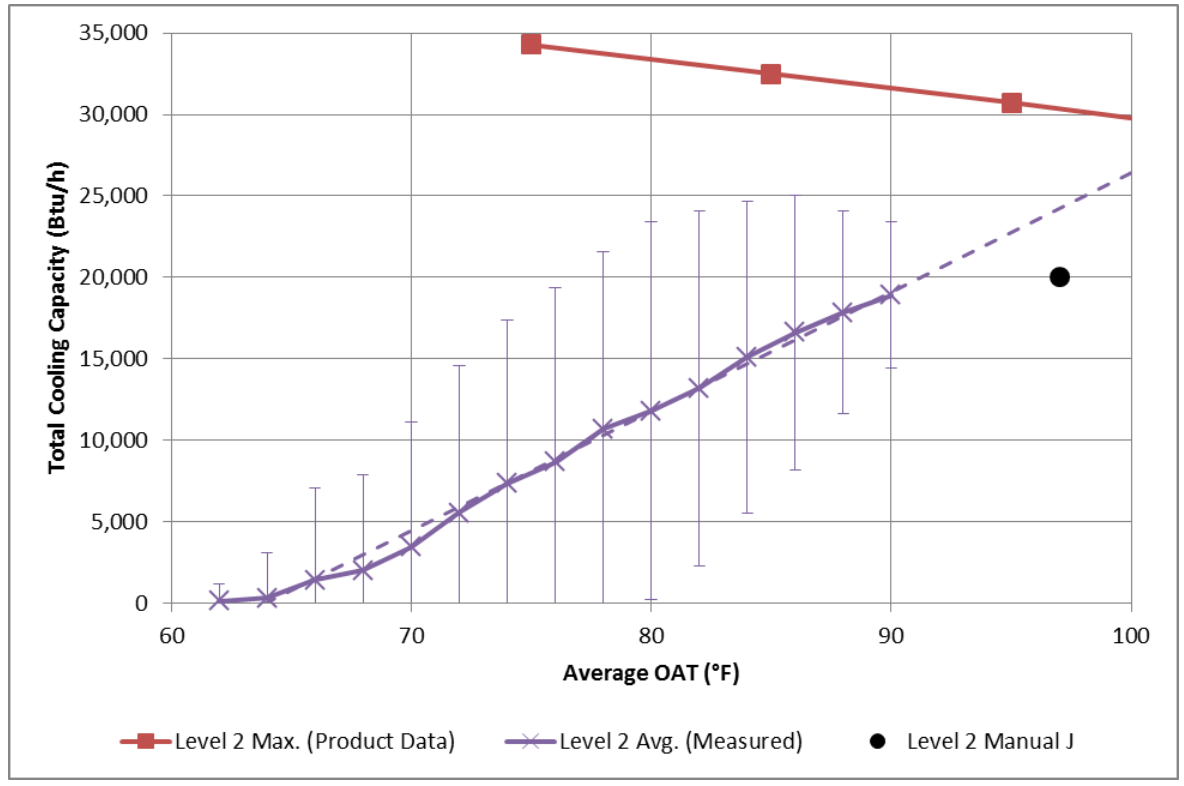

Fig. 4. Level-2 Maximum Total Cooling Capacity and Average Hourly Delivered Capacity 
In contrast to the heating season where the level-1 unit carried some of the heating load of the level-2 unit, it is likely that the level-2 unit carried some of the cooling load of the level-1 unit in the cooling season. This would explain the lower than expected load on the downstairs unit and higher than expected load on the upstairs unit. This phenomenon likely varies from home to home based on the location of internal loads, the geometry of the home, how much open space there is between floors, and many other factors. Due to this, it would be extremely challenging to accurately predict the impact of this phenomenon in a home without obtaining more detailed data than what is typically available for a Manual $\mathrm{J}$ load calculation. With that being said, it is something that designers should keep in mind when dealing with multiple story homes.

\section{RESULTS AND ANALYSIS}

The analysis portion of this report will focus on dehumidification performance of the heating load sized heat pumps. The weather normalized energy use of the two variable capacity heat pump systems in comfort mode and efficiency mode will be compared to that of the previous systems that were installed. The weather-normalization process allows for direct energy savings comparison of the variable capacity heat pumps in their two different operating modes and the prior single-speed systems.

The performance of the equipment is evaluated based on energy efficiency as well as its ability to maintain a comfortable level of humidity inside the home during the cooling season. As a point of reference, the Air-Conditioning, Heating, and Refrigeration Institute (AHRI) seasonal energy efficiency ratio (SEER) and heating seasonal performance factor (HSPF) ratings for the tested heat pumps (AHRI 2012) are shown in Table 1 along with their corresponding seasonal coefficients of performance (SCOP). HVAC equipment performance will vary according to the conditions under which it operates (as, for example, a vehicle's gas mileage will vary according to speed and terrain). Federal rating standards are designed to reflect equipment performance for a set of typical conditions. It is to be expected, therefore, that the measured performance of a particular piece of equipment in service will vary somewhat from the performance under federal rating conditions. For consistency, the measured data was normalized for outdoor and return air temperatures as described in Munk et al (2013).

Table 1: AHRI Ratings

\begin{tabular}{ccccc}
\hline Unit & $\begin{array}{c}\text { AHRI Rated Cooling Efficiency } \\
\text { SEER } \\
\text { (Btu/Wh) }\end{array}$ & $\begin{array}{c}\text { SCOP } \\
\text { (W/W) }\end{array}$ & $\begin{array}{c}\text { AHRI Rated Heating Efficiency } \\
\text { HSPF } \\
\text { (Btu/Wh) }\end{array}$ & $\begin{array}{c}\text { SCOP } \\
(\mathbf{W} / \mathbf{W})\end{array}$ \\
\hline Level 1 & 19.1 & 5.6 & 10.5 & 3.1 \\
Level 2 & 19.2 & 5.6 & 10.5 & 3.1 \\
\hline
\end{tabular}

\subsection{ENERGY USE}

To allow direct comparison of the energy consumption of the systems, the data is normalized based on OAT to account for variations in the weather of different years. This is achieved by plotting the daily heat pump energy use against the average daily OAT and fitting separate polynomials to the heating and cooling data. The typical meteorological year (TMY3) average daily temperatures for Knoxville, 
Tennessee (NREL, 2012), are then used as inputs to the polynomials to generate heating, cooling, and annual energy uses.

Fig. 5 shows annual heating and cooling energy use of the original single-stage heat pumps and the variable capacity heat pumps in both the comfort and efficiency modes. The data included in this section spans from December 2011 to September 2012 for the original single-stage heat pumps, and from December 2012 to September 2013 for the variable capacity heat pumps. The variable capacity system offers a $25 \%$ reduction in heating season energy use when operating in comfort mode; this goes up to $32 \%$ in efficiency mode. As with the heating season, the variable capacity heat pumps also show significant energy savings during the cooling season. The variable capacity system offers a $41 \%$ reduction in energy use when operating in comfort mode, and a $44 \%$ reduction in efficiency mode operation. On an annual basis, the variable capacity system operated in comfort mode shows an annual savings of 2,989 $\mathrm{kWh}$ or $31 \%$ over the baseline system. When operated in efficiency mode, the energy savings increase to $3,489 \mathrm{kWh}$ or $37 \%$ over the baseline system.

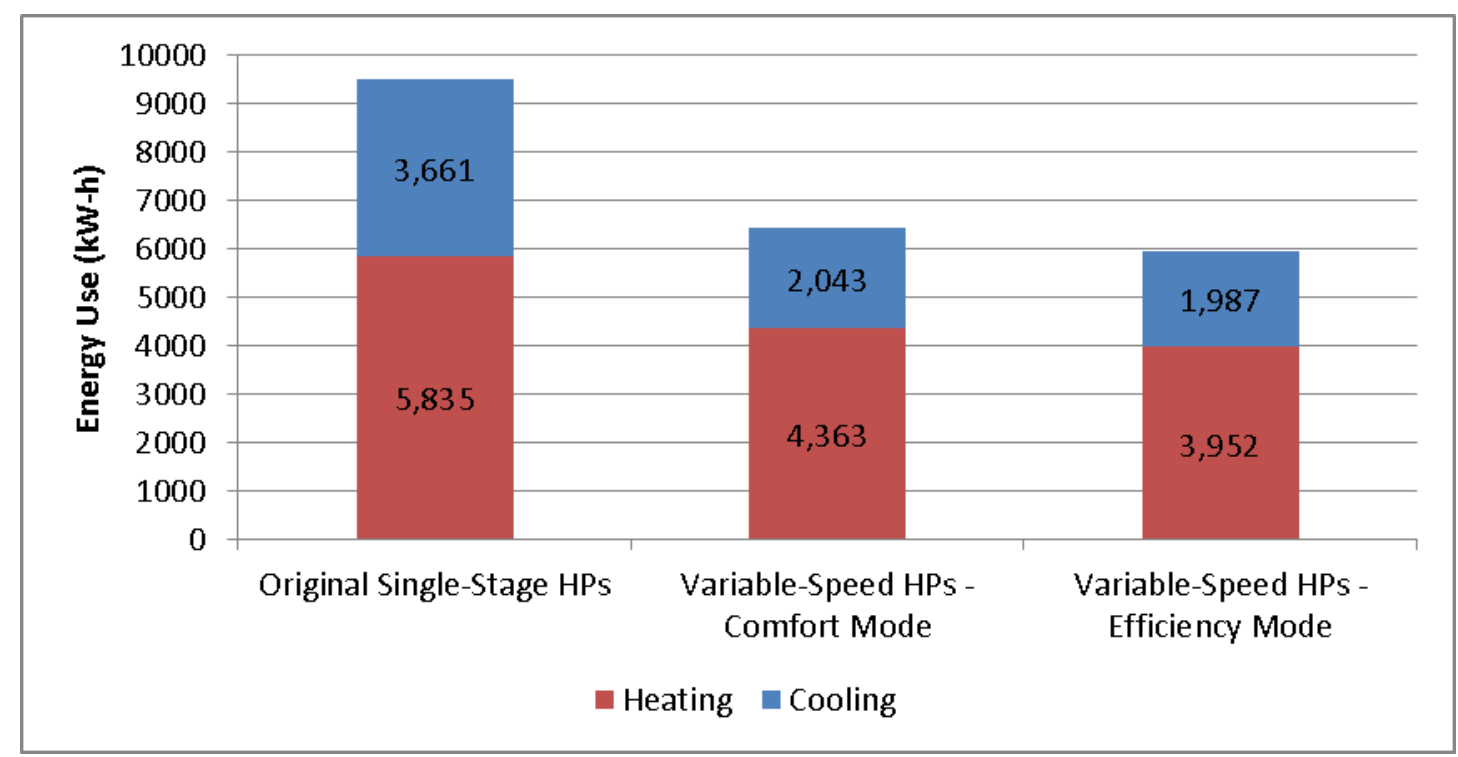

Fig. 5. CC1 TMY3 Annual Energy Use for Knoxville, Tennessee

Fig. 6 shows the resistance heat use of both the original single-stage heat pumps and the variable capacity heat pumps. For the variable capacity system, Fig. 6 shows two curves, for the first, resistance heat use in defrost cycles is enabled, and for the second it is disabled. In the first case, resistance heat is used to prevent cold air from being blown into the house. There is only a slight difference in energy use when moving from the first case to the second; this is because when resistance heat use is disabled during defrost cycles, cold air is blown into the house and the heat pump must compensate for this by providing additional heating to keep the house at the desired indoor temperature setpoint. When it was very cold outside, the drop in the indoor temperature during the defrost cycle was often enough to trigger supplemental resistance heat when the heat pump switched back to the heating mode after the defrost cycle. This sometimes resulted in more resistance heat use than if it would have been enabled during the defrost cycle as seen by the points with average daily temperatures below $35^{\circ} \mathrm{F}$. 
The variable capacity system has a variable-speed compressor that can run at higher speeds when the OAT is lower and lower speeds when the OAT is higher; this feature reduces the need for supplemental resistance heat. A $68 \%$ reduction in resistance heat use is achieved over the heating season; this reduction can be seen in Fig. 6 . The fact that these $\mathrm{CC} 1$ variable capacity units are intentionally sized for the heating season, as discussed in the equipment sizing section of this report, also contributes to the reduction in resistance heat use.

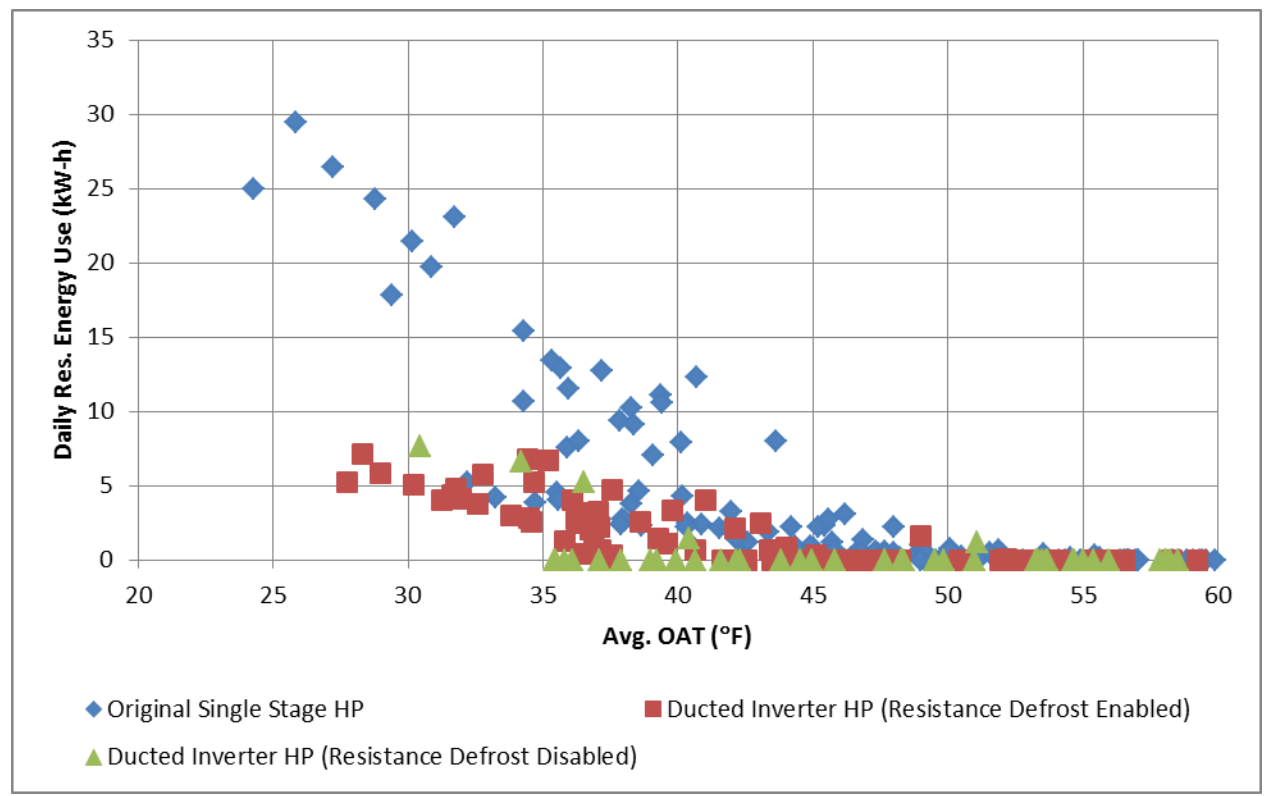

Fig. 6. CC1 Resistance Heat Use

\subsection{HEATING SEASON EFFICIENCY}

The average heating performance factor (HPF) for each unit was calculated for the time period of December 8, 2012, to May 1, 2013. For consistency, the measured efficiencies were normalized for OAT and results are shown in Table 2. The initial data for the level 2 unit showed its efficiency was $22 \%$ lower than the level 1 unit. After thoroughly checking all of the instrumentation on the unit, the charge was checked in early April 2013. The unit was found to be about $12.5 \%$ low on charge and heating data from before and after the charge was added is plotted in Fig. 7. The data indicates a minor efficiency improvement of $1-5 \%$, but not enough to account for the large performance discrepancy seen when comparing the rated HSPF and the OAT normalized HPF. In the following heating season, an OAT sensor fault was shown on the thermostat that required changing the control board in the outdoor unit. Data measured after this change showed a significant improvement in heating efficiency and these results are shown in Table 2.

Table 2 CC1 Heating Efficiency

\begin{tabular}{|c|c|c|}
\hline Mode & $\begin{array}{c}\text { Average } \\
\text { Measured } \\
\text { HPF } \\
\text { (Btu/Wh) }\end{array}$ & $\begin{array}{c}\text { OAT Normalized } \\
\text { Average HPF } \\
\text { (Btu/Wh) }\end{array}$ \\
\hline
\end{tabular}




\begin{tabular}{cccc}
\hline Level-1 & Efficiency & $10.8 \pm 0.5$ & 10.1 \\
& Comfort & $10.0 \pm 0.4$ & 9.4 \\
Level-2 & Efficiency & $8.8 \pm 0.4^{1}$ & 8.8 \\
& Comfort & N/A & N/A \\
\hline
\end{tabular}

${ }^{1}$ Data used is from Jan.-Mar. 2014

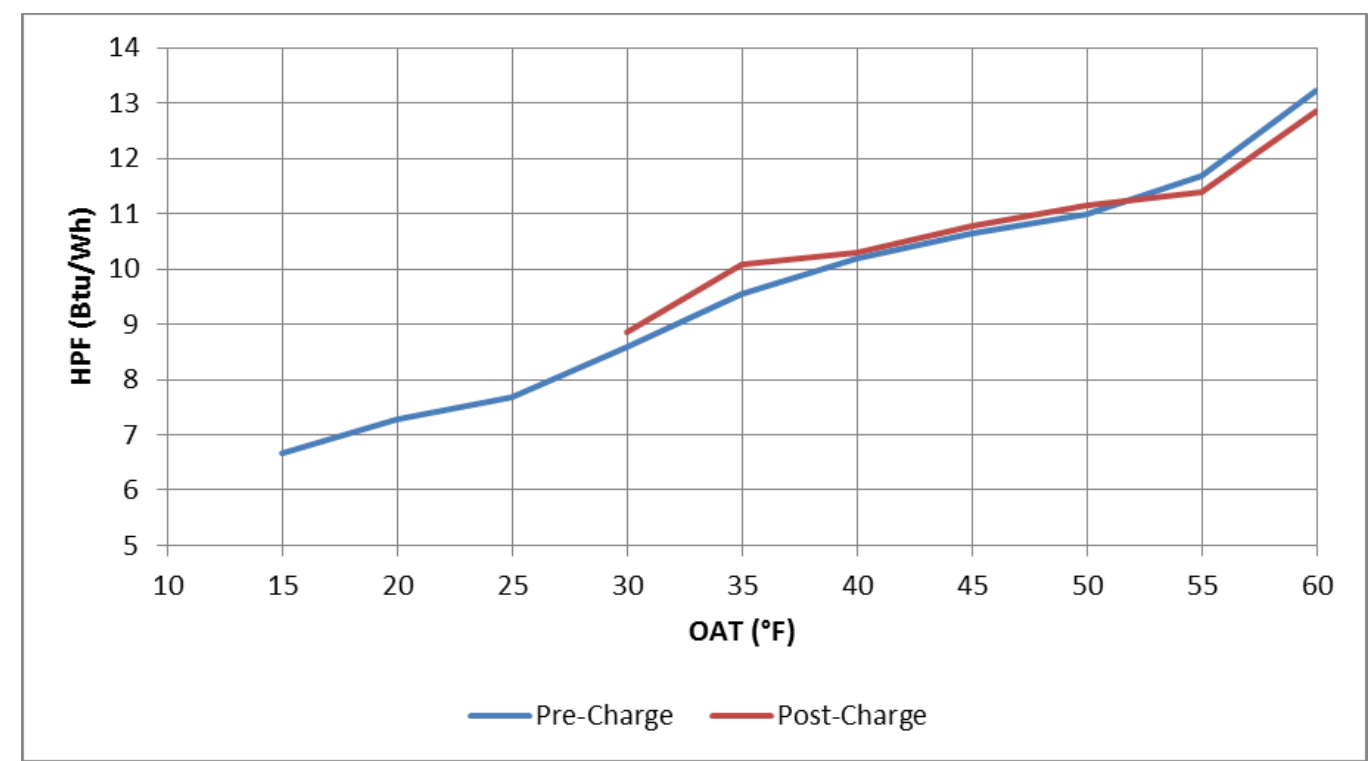

Fig. 7. CC1 Level-2 Heating Efficiency Before and After Added Charge

Despite differences in sizing and delivered heating loads, both units ran for similar amounts of time throughout the course of a day, as represented in Fig. 8 by the similar part load ratios (PLR) at a given average outdoor temperature. This indicates that the length of the cycles and overall runtime were not a factor in the lower heating performance of the level-2 unit.

Note in Fig. 8, there are distinct horizontal bands of data at various PLRs. Both units had cycle lengths that clustered very closely around five minute intervals, which explains the 12 distinct bands of data when looking at the PLR over a period of 60 minutes. This may be the result of the control logic of the thermostat. 


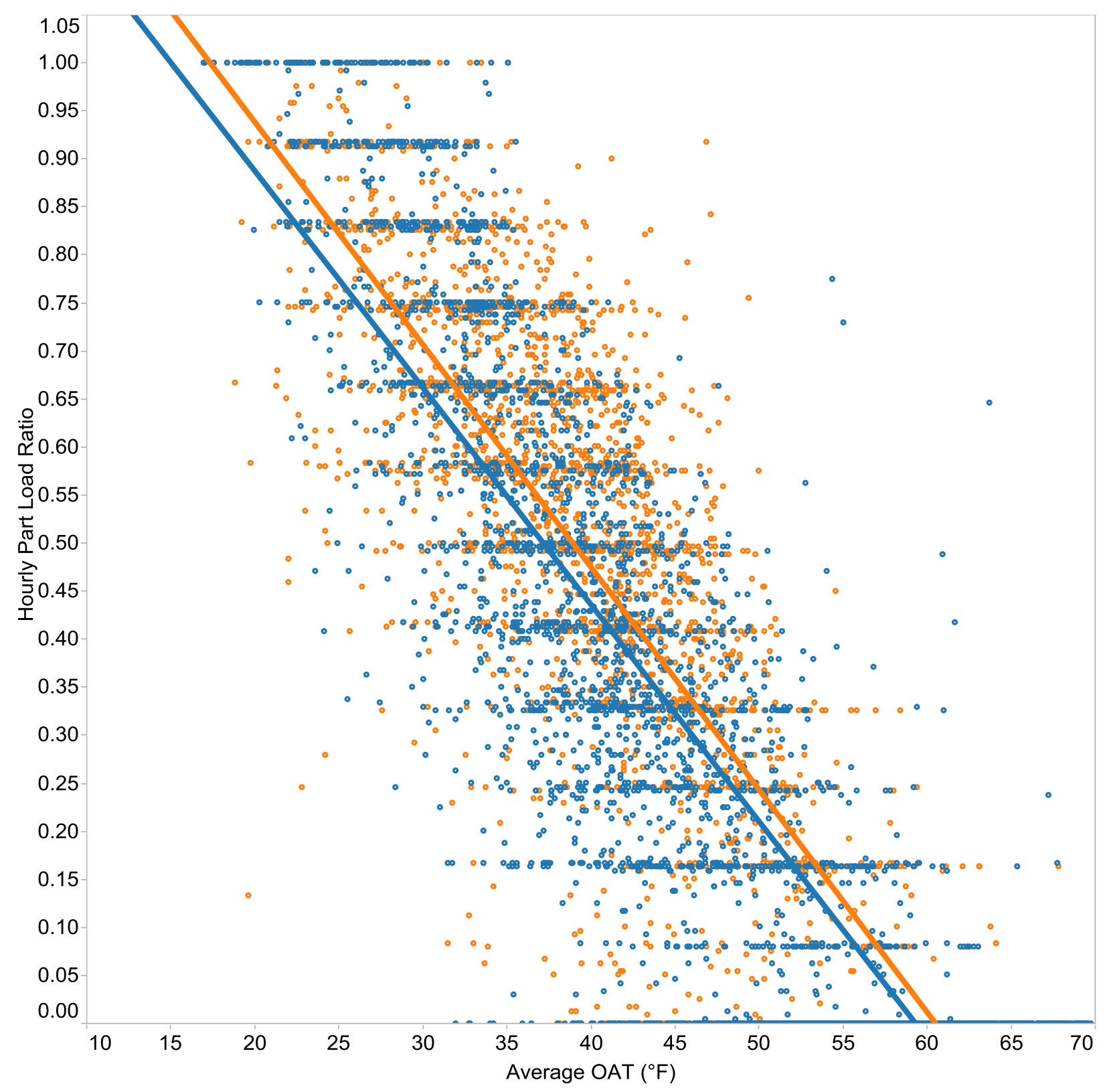

Level 1 PLR

Level 2 PLR

Fig. 8. CC1 Level-1 and Level-2 Hourly Part Load Ratios

\subsection{COOLING SEASON EFFICIENCY}

The average cooling energy efficiency ratio (EER) was calculated from the measured data spanning from May 1, 2013, to September 1, 2013, and is shown in Table 3. As with the heating season data, the average EER for the cooling season was normalized based on the OAT using the Air-Conditioning, Heating, and Refrigeration Institute's (AHRI) temperature bin weightings for the Seasonal Energy Efficiency Ratio (SEER) calculation. The cooling data was also corrected for the difference in return air conditions. 
Table 3. CC1 Cooling Efficiency

\begin{tabular}{cccc}
\hline Mode & $\begin{array}{c}\text { Measured } \\
\text { Avg. EER } \\
\text { (Btu/Wh) }\end{array}$ & $\begin{array}{c}\text { OAT and Return } \\
\text { Wet-Bulb } \\
\text { Normalized Avg. } \\
\text { EER (Btu/Wh) }\end{array}$ \\
\hline \multirow{2}{*}{ Level-1 } & Efficiency & $16.6 \pm 2.7$ & 16.6 \\
& Comfort & $16.2 \pm 1.8$ & 16.1 \\
Level-2 & Efficiency & $17.9 \pm 3.0$ & 17.6 \\
& Comfort & $16.4 \pm 2.0$ & 16.8 \\
\hline
\end{tabular}

Both units showed very similar cooling performance despite being sized very differently compared to the cooling load and therefore cycling at different intervals. Fig. 9 shows the hourly PLR (minutes of runtime in an hour divided by 60) plotted against the average OAT. It can be seen that the level-2 unit runs for a continuous hour quite frequently when the OAT is above $78^{\circ} \mathrm{F}$, while the level- 1 unit rarely runs for more than 20 minutes out of an hour. The two distinct horizontal bands of data for the level-1 unit illustrate hours that the unit ran 1- or 2-cycles during the hour. The minimum cycle length on this unit appears to be approximately 9.5 minutes based on the data, which corresponds with the bands of data at roughly 0.16 and 0.32 PLR. The cooling efficiency and PLR data indicate that there is no measurable cooling efficiency penalty between a unit that is modestly oversized and one that is extremely oversized. 


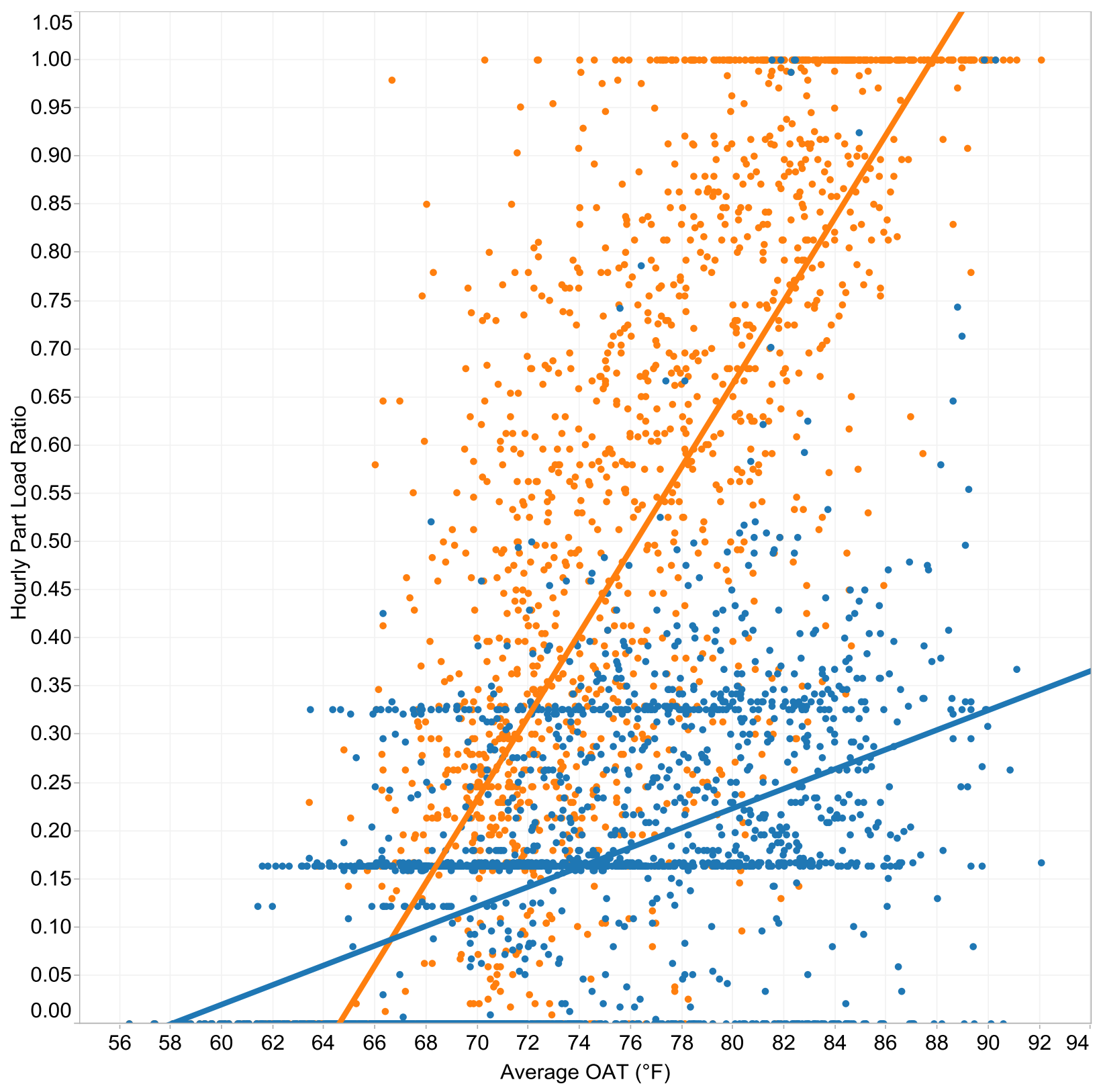

Level 1 PLR

Level 2 PLR

Fig. 9. CC1 Cooling Season Hourly Part Load Ratios

\subsection{COOLING SEASON COMFORT}

Fig. 10 shows the daily runtime in minutes for both $\mathrm{CC} 1$ units. During the hottest days, the upstairs unit was running almost three times longer per day than the downstairs unit. The low runtime for the downstairs heat pump is partly a consequence of sizing the unit for the heating load, as it is now sized far above the cooling load. Additionally, the second floor system runs much longer than the first floor system because it provides most of the cooling in the house; warm air rises and cold air falls, therefore the upstairs heat pump provides most of the capacity needed to maintain the $76^{\circ} \mathrm{F}$ set point. In Fig. 11, the 
sensible heat ratios of both heat pumps are plotted. There is only a 0.03 difference in the average sensible heat ratio (SHR) of the two heat pumps; this suggests that the downstairs heat pump's performance in latent heat removal does not suffer as a result of intentional over-sizing, even though it is significantly more over-sized than the upstairs unit.

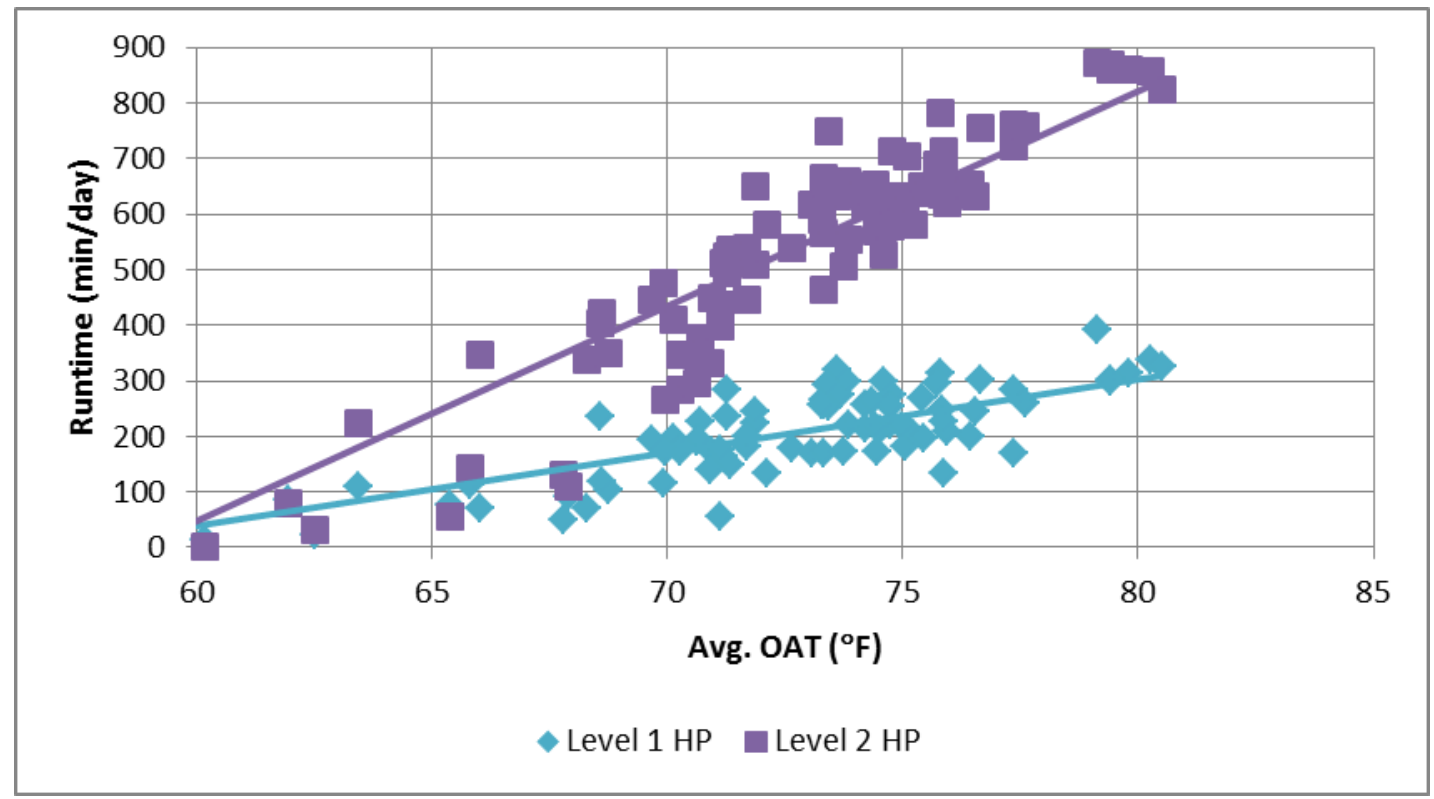

Fig. 10. Daily Heat Pump Runtime

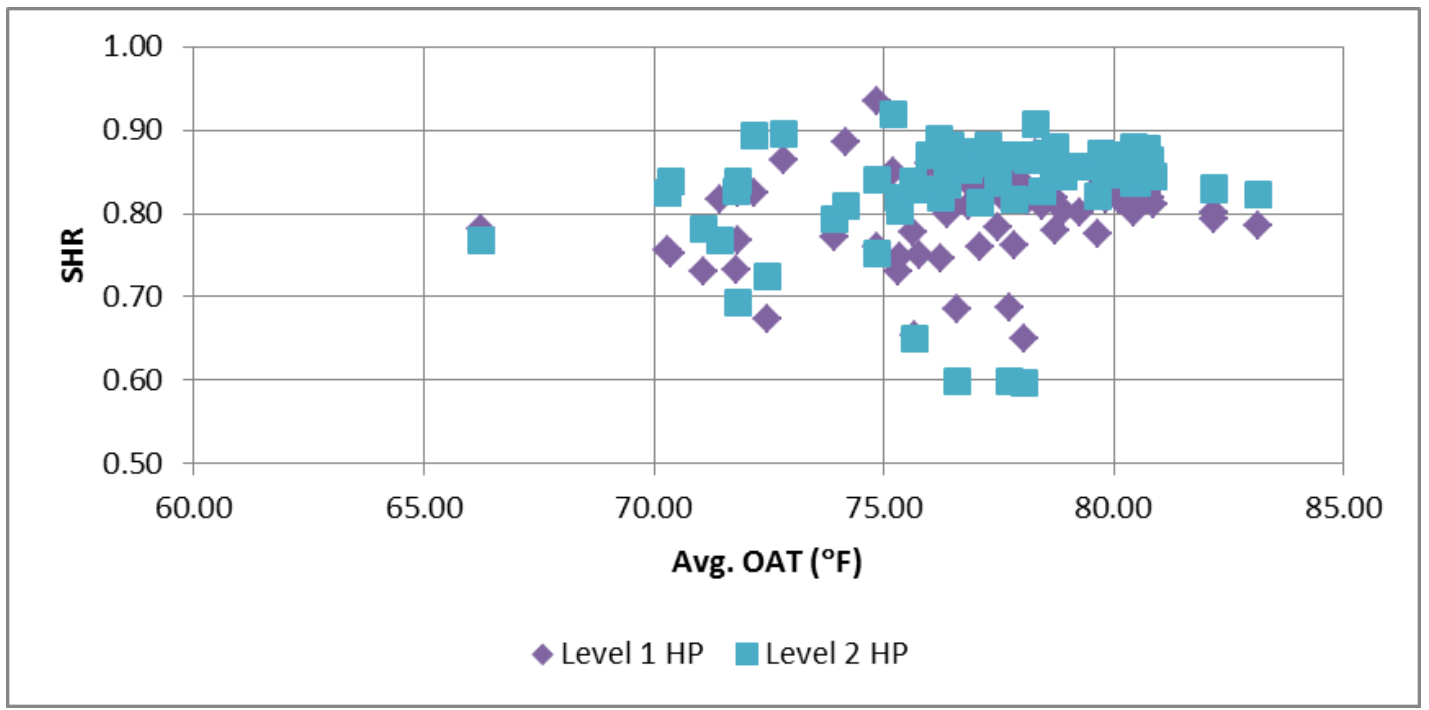

Fig. 11. Heat Pump Sensible Heat Ratio

In Fig. 12 and Fig. 13, the indoor humidity levels are plotted against the outdoor temperature for both the upstairs and downstairs systems operating in comfort and efficiency modes. When operating in comfort mode, no distinguishable difference in humidity levels can be seen in comparison to the baseline case. In the baseline case, the average daily indoor relative humidity (RH) levels are $46 \%$ and $44 \%$ for the downstairs and upstairs respectively. Under the tested conditions for the variable-speed heat pumps, the 
average $\mathrm{RH}$ values change to $45 \%$ and $44 \%$ for downstairs and upstairs respectively in comfort mode operation, and 50\% and 49\% downstairs and upstairs respectively in efficiency mode operation. This leads to the conclusion that for the average home in mixed-humid climates, there is effectively no penalty in dehumidification associated with sizing for the heating season load during comfort mode operation. In efficiency mode operation for the variable speed HVAC system evaluated in this study, the increase in average daily RH is due to the reduced rate of latent heat removal which results in additional energy savings. It is important to note that with both the baseline heat pumps and ducted inverter heat pumps, the indoor temperature set point remained at a constant $76^{\circ} \mathrm{F}$.

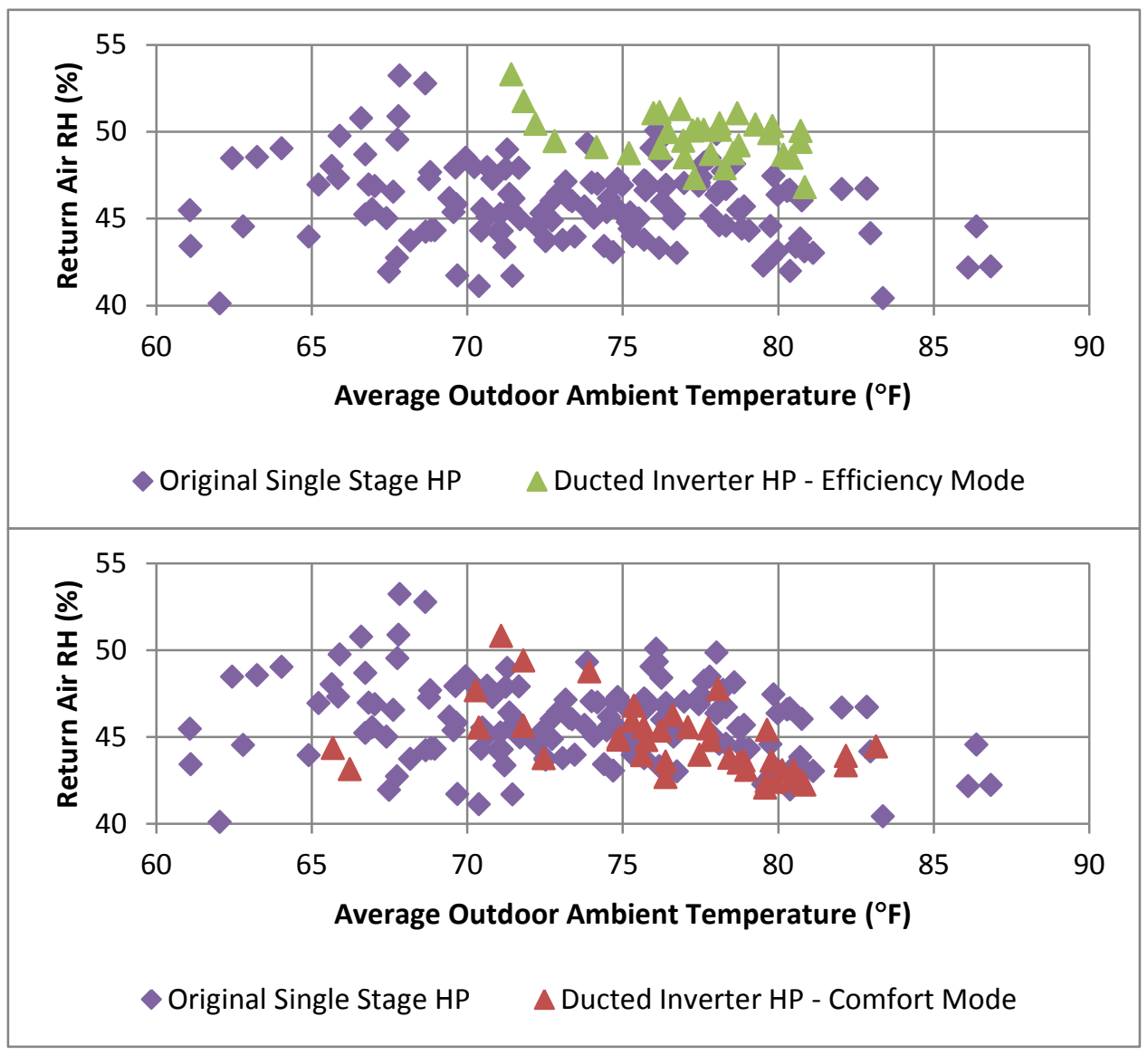

Fig. 12. Level-1 Indoor Relative Humidity Levels 


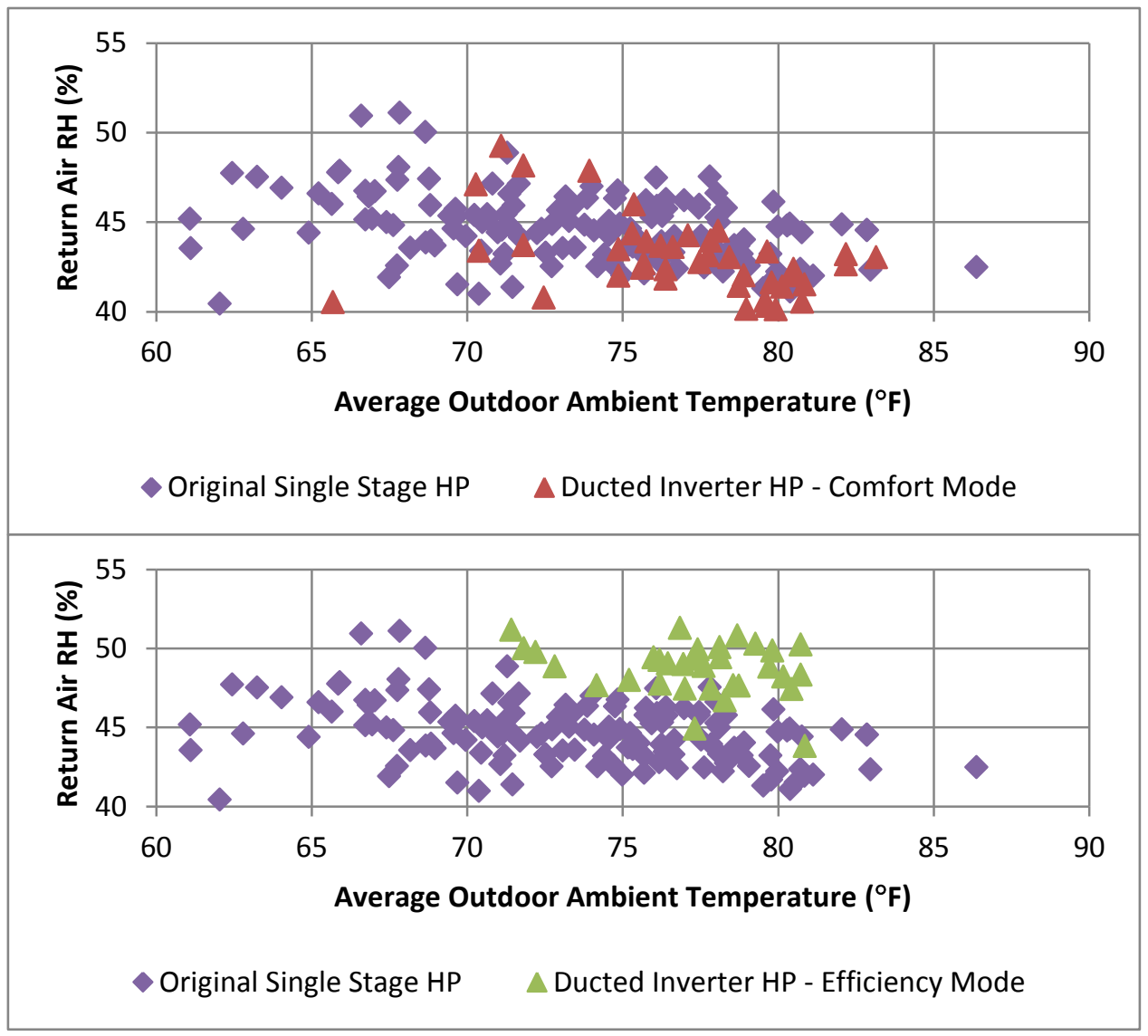

Fig. 13. Level-2 Indoor Relative Humidity Levels

Fig. 14 below demonstrates the difference in operation between comfort and efficiency modes for the ducted inverter. In comfort mode, the ducted inverter is able to achieve lower levels of SHR and slightly lower RH levels. More latent heat removal occurs in comfort mode than efficiency mode; this is how the additional energy savings attained in efficiency mode operation are achieved. In both modes of operation, the $\mathrm{RH}$ level is well below $60 \%$, with an indoor temperature set point of $76^{\circ} \mathrm{F}$, this ensures adequate human comfort. 


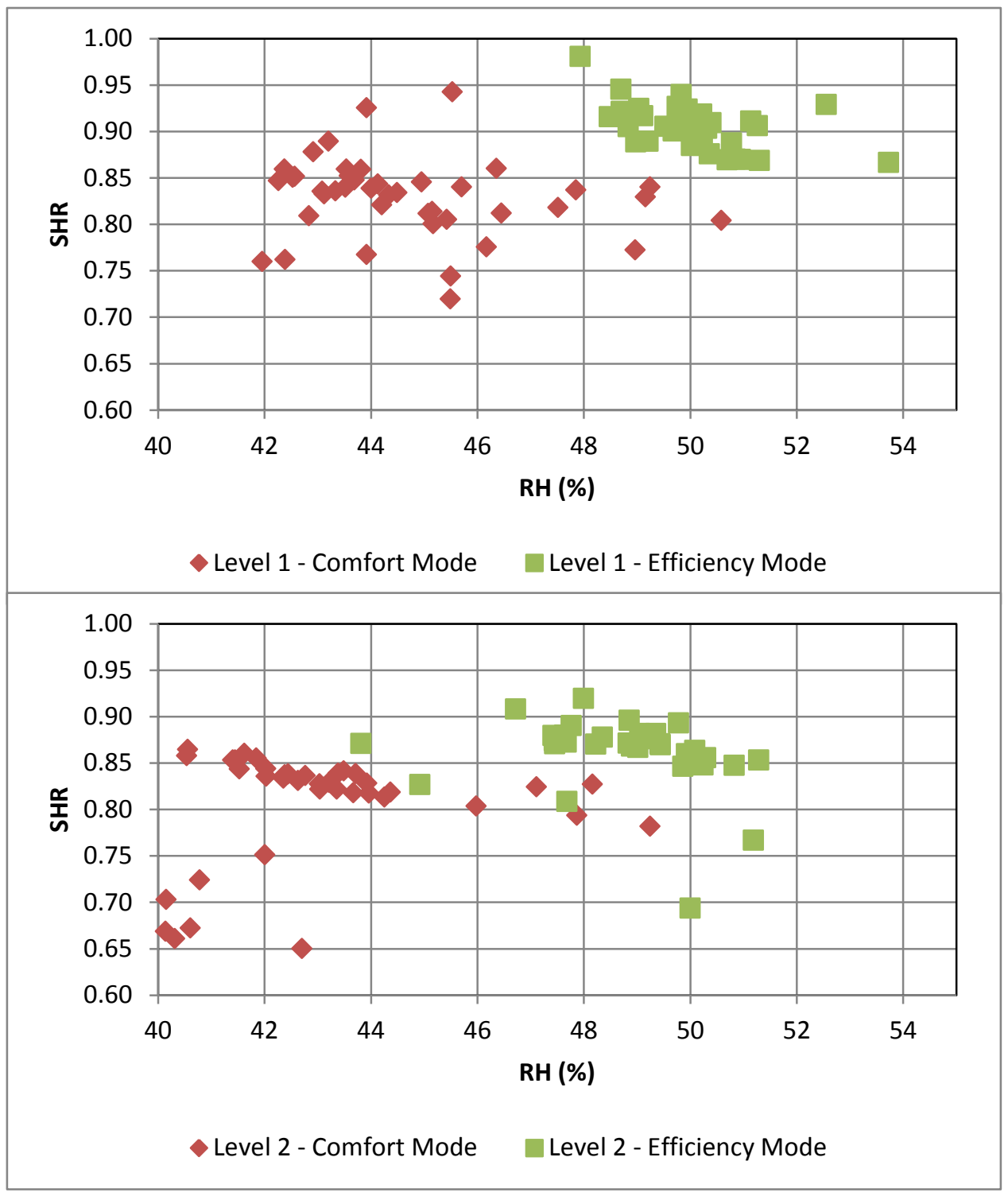

Fig. 14. Sensible Heat Ratio vs. Indoor Relative Humidity

\subsection{Energy Savings Potential}

Since it is unlikely that a homeowner would install two variable-speed heat pumps in a home due to higher first costs, the cost savings analysis was performed assuming a single variable-speed heat pump would be serving the entire home. The savings associated with the avoidance of supplemental resistance heat due to sizing the heat pumps for the heating load rather than the cooling load was estimated at 160 $\mathrm{kWh}$, or $4 \%$, for a typical meteorological year (TMY) in Knoxville, Tennessee. This estimation was made by running a Monte-Carlo type simulation for the heating load of each hour in the TMY data file based on the average measured heating load at that outdoor air temperature and the average standard deviation of the measured heating load data assuming a normal distribution. The manufacturer's product data for the available heat pump capacity was used for a single, 3-ton unit since it was capable of meeting the Manual J design cooling load for both floors. This house experienced very similar heating and 
cooling loads of approximately $28 \mathrm{kBtu} / \mathrm{h}$, which is unexpected because the Manual $\mathrm{J}$ calculations indicated that the heating load would be about $50 \%$ larger than the cooling load. The similarity of the heating and cooling loads significantly limits the need to size a unit differently for the heating load compared to the cooling load and therefore reduces the potential for savings related to resistance heat use. Compounding this is the fact that the particular heat pumps tested have relatively high heating capacities at low temperatures relative to their rated cooling capacity. In general, this is a beneficial feature of some variable-speed heat pumps, but it does diminish the savings possible from supplemental resistance heat avoidance in climates with mild winters. Some variable-speed heat pumps on the market do not have such large heating capacities relative to their cooling capacity and would likely yield increased savings due to sizing them to the heating load.

In addition, these savings are likely on the conservative side as they do not account for any efficiency improvement due to a larger heat pump running at part load conditions more often, which, assuming the same rated efficiency between sizes, should result in increased efficiency in both heating and cooling modes.

\section{CONCLUSIONS}

This report summarizes the heating and cooling season performance of variable capacity heat pumps installed in a research home in Knoxville, Tennessee. The energy use analysis indicates that the variable capacity heat pump systems are performing significantly better than the prior single-speed heat pumps, offering an energy savings potential of up to $37 \%$ when operated in efficiency mode. However, this is lower than the expected savings due to the lower performance of the level-2 variable speed heat pump in the heating mode. The analysis of the variable speed heat pump systems operating in comfort mode and efficiency mode indicates an energy savings potential of $7 \%$ when operating in efficiency mode over comfort mode; this comes at the price of reduced control over indoor humidity.

The comfort assessment indicates that the variable capacity heat pumps allow for intentional oversizing relative to the cooling load with no associated penalty in latent heat removal while operating in the comfort mode. This intentional oversizing can reduce or eliminate the need for supplemental electric resistance heat use in the heating season, and reduces peak hourly power draw which is of particular interest to utilities. Due to imbalances in the heating and cooling loads and the limited capacity range of ducted, split-system heat pumps, it is difficult in most climates to have a heat pump that is appropriately sized for both heating and cooling. This is particularly true in two-story homes with separate space conditioning systems for each level as seen in this study. Variable capacity heat pumps are able to mitigate this problem by allowing the unit to run at reduced capacity for longer periods of time thereby reducing cycling losses that exist with single speed heat pumps.

When heating loads are larger than cooling loads, single-speed heat pumps that are sized to the cooling load cannot satisfy the heating load without the use of supplemental heat. As a whole, our research home had unexpectedly balanced heating and cooling loads, resulting in relatively small savings associated with supplemental heat avoidance. However, there are likely additional unaccounted for savings in both the heating and cooling modes due to increased operation at part load conditions that yield higher efficiencies than full-load operation. Future work will use simulations to determine the savings potential of variable- 
speed heat pumps sized to heating loads in other climates and determine if indoor humidity is adversely affected by this sizing strategy.

In 2-story homes in the mixed-humid climate with a separate HP serving each level, it may make the most sense economically to replace the first floor HP with a variable-speed unit sized to the first floor heating load prior to investing in upgrades to their upstairs heat pump. It can be seen from the data that heating costs outweigh cooling costs, and the significantly higher heating load compared to the cooling load of the first floor make it an ideal candidate for a variable-speed heat pump. This should maximize the winter savings potential while also reducing the risk of humidity issues in the summer.

\section{ACKNOWLEDGEMENTS}

This work was funded and supported by the United States Department of Energy (DOE) and the Tennessee Valley Authority (TVA). Special thanks go to TVA program manager David Dinse for providing this unique research house as a testing platform.

\section{REFERENCES}

AHRI. 2012. Directory of Certified Product Performance: Heat Pumps and Heat Pump Coils. AirConditioning, Heating, and Refrigeration Institute. https://www.ahridirectory.org/ahridirectory/pages/home.aspx. October, 2012.

Boudreaux, P.R., A.C. Gehl, J.E. Christian. 2012. Occupancy Simulation in Three Residential Research Houses. ASHRAE Transactions, 118, (2): 625-637.

Elite Software Development, Incorporated. 2011. RHVAC Version 9.0 Residential and Light Commercial HVAC Loads Program User's Manual. College Station, Texas.

International Code Council. (2006). 2006 International Energy Conservation Code. International Code Council.

Munk, J.D, C.K. Halford, R.K. Jackson. Component and System Level Research of Variable Capacity Heat Pumps. Oak Ridge National Laboratory, 2013.

National Renewable Energy Laboratory. (2012.). National Solar Radiation Data Base. Retrieved October 2012, from http://rredc.nrel.gov/solar/old_data/nsrdb/1991-2005/tmy3/by_state_and_city.html

Rutkowski, H. (2006). Residential Load Calculations Manual J 8th Ed. Air Conditioning Contractors of America. 
